\title{
Clinical Study \\ Hearing Benefit in Allograft Tympanoplasty Using Tutoplast Processed Malleus
}

\author{
Anja Lieder and Wolfgang Issing \\ Department of Otolaryngology, Freeman Hospital, Freeman Road, High Heaton, Newcastle upon Tyne NE7 7DN, UK \\ Correspondence should be addressed to Wolfgang Issing; wolfgang.issing@nuth.nhs.uk
}

Received 24 September 2013; Revised 16 December 2013; Accepted 6 January 2014; Published 13 February 2014

Academic Editor: Leonard P. Rybak

Copyright (C) 2014 A. Lieder and W. Issing. This is an open access article distributed under the Creative Commons Attribution License, which permits unrestricted use, distribution, and reproduction in any medium, provided the original work is properly cited.

\begin{abstract}
Objectives. Tutoplast processed human cadaveric ossicular allografts are a safe alternative for ossicular reconstruction where there is insufficient material suitable for autograft ossiculoplasty. We present a series of 7 consecutive cases showing excellent air-bone gap closure following canal-wall-down mastoidectomy for cholesteatoma and reconstruction of the middle ear using Tutoplast processed malleus. Patients and Methods. Tympanoplasty with Tutoplast processed malleus was performed in seven patients to reconstruct the middle ear following canal-wall-down mastoidectomy in a tertiary ENT centre. Main Outcome Measures. Hearing improvement and recurrence-free period were assessed. Pre-and postoperative audiograms were performed. Results. The average pre operative hearing loss was $50 \pm 13 \mathrm{~dB}$, with an air-bone gap of $33 \pm 7 \mathrm{~dB}$. Post operative audiograms at 25 months demonstrated hearing thresholds of $29 \pm 10 \mathrm{~dB}$, with an air-bone gap of $14 \pm 6 \mathrm{~dB}$. No prosthesis extrusion was observed, which compares favourably to other commercially available prostheses. Conclusions. Tutoplast processed allografts restore conductive hearing loss in patients undergoing mastoidectomy and provide an excellent alternative when there is insufficient material suitable for autograft ossiculoplasty.
\end{abstract}

\section{Introduction}

Human cadaveric allografts have been used in middle ear reconstruction for half a century. They fully integrate into the middle ear and may be used to reconstruct the ossicular chain where there is insufficient autologous material. Tutoplast processed ossicular allografts (Tutoplast Ossicula auditus) consist of dehydrated human malleus or incus and provide a matrix for new bone formation through bone remodelling. They are derived from selected donors using the Tutoplast process. This process involves osmotic destruction of tissue cells, followed by denaturation using sodium hydroxide and hydrogen peroxide to inactivate all pathogens, and finally dehydration and sterilization by gamma irradiation. The Tutoplast process inactivates all living organisms and spores from donated tissue and achieves Sterility Assurance Level of $10^{-6}$. Each transplant can be tracked back to the original donor $[1,2]$. Tutoplast Ossicula auditus is licensed as a medical product in Germany and fulfils European Union and USA medical drug regulations.
We present a series of 7 consecutive cases demonstrating excellent long-term hearing improvements in tympanoplasty using Tutoplast processed malleus to reconstruct the middle ear following mastoidectomy.

\section{Patients and Methods}

Seven consecutive patients with cholesteatoma aged 11-69 years (four male, three female) underwent canal-wall-down mastoidectomy and tympanoplasty between May 2009 and January 2011. Two cases were revisions. All patients had canalwall-down mastoidectomy for removal of cholesteatoma, followed by ype III tympanoplasty including myringoplasty with tragal perichondrium in a single-stage procedure. This would entail the placement of a Tutoplast processed malleus (Tutoplast Ossicula auditus, Tutogen Medical GmbH, Neunkirchen, Germany) onto the stapes if the patient's own ossicles were found to be either absent, eroded or unsuitable for an autograft. One patient had additional 
TABLE 1: Comparison between pre- and postoperative audiograms and assessment of air-bone gap.

\begin{tabular}{|c|c|c|c|c|c|c|c|c|c|}
\hline & \multicolumn{9}{|c|}{ Patient } \\
\hline & 1 & 2 & 3 & 4 & 5 & 6 & 7 & Mean & $\mathrm{SD}$ \\
\hline \multicolumn{10}{|c|}{ Operated ear } \\
\hline Preoperative hearing (air conduction; $500-4000 \mathrm{~Hz}$ ) & 50 & 41 & 55 & 73 & 54 & 38 & 36 & 49.5 & 12.7 \\
\hline Preoperative air-bone gap $(500-4000 \mathrm{~Hz})$ & 30 & 23 & 28 & 43 & 38 & 34 & 35 & 32.7 & 6.6 \\
\hline Follow-up (months) & 34 & 26 & 29 & 29 & 20 & 22 & 15 & 25 & 6 \\
\hline Postoperative hearing (air conduction; $500-4000 \mathrm{~Hz}$ ) & 28 & 28 & 39 & 45 & 28 & 19 & 19 & $29.1^{\mathrm{a}}$ & 9.7 \\
\hline Postoperative air-bone gap $(500-4000 \mathrm{~Hz})$ & 18 & 5 & 24 & 14 & 15 & 9 & 13 & $13.8^{\mathrm{b}}$ & 6.0 \\
\hline Air-bone gap closure achieved & 13 & 18 & 4 & 29 & 23 & 25 & 23 & 18.9 & 8.5 \\
\hline
\end{tabular}

${ }^{\mathrm{a}} P=0.0061 ;{ }^{\mathrm{b}} P=0.00012$. Bold: Mean values. Italic: Standard deviation.

reconstruction of posterior canal wall using tragal cartilage. All patients had their ear dressed with 2 silastic sheets, one being placed in the mastoid cavity to facilitate epithelialisation of the cavity and the other to cover the tympanic membrane. Bismuth iodine paste gauze dressing was applied into the external auditory meatus for 2-3 weeks. Once sufficient healing was ascertained, patients were instructed in the Valsalva manoeuvre and were encouraged to perform it 20-30 times per day.

Hearing assessment was by pure tone audiograms in accordance with the British Society of Audiology recommended procedure (2004). Values are given in Decibel Hearing Level (dB HL) for testing frequencies of 250, 500, 1000, 2000, 4000, and $8000 \mathrm{Hertz}(\mathrm{Hz})$. Air-bone gaps were calculated in accordance with the American Academy of Otolaryngology-Head and Neck Surgery (AAO-HNS) 1995 guideline. The testing frequency of $3000 \mathrm{~Hz}$ was substituted with $4000 \mathrm{~Hz}$. Audiograms were read by two observers independently. Average hearing levels are given in $\mathrm{dB} \mathrm{HL}$ and standard deviations are applied where appropriate. Where applicable, Student's $t$-test (equal sample size, unequal variance) was performed and $P$ values were given.

\section{Ethical Considerations}

Written consent, including the use of Tutoplast Ossicula auditus, was obtained. All investigations and procedures were performed according to best clinical practice and the medical principles of the Declaration of Helsinki. The National Research Ethics Service of the United Kingdom has confirmed that formal ethics approval procedure is not required (NRES Ref 04/26/31) as this is a retrospective study using a fully licensed product.

\section{Results}

Postoperative complications were not observed. The stapes suprastructure was fully intact in six patients. There was partial destruction of the stapes suprastructure in one patient, with one crus being present, and, in this case, the prosthesis was placed on the preserved crus.

The average preoperative hearing loss (air conduction) was $49.5 \pm 12.7 \mathrm{~dB}(36-73 \mathrm{~dB})$. The average preoperative airbone gap was $32.7 \pm 6.6 \mathrm{~dB}(23-43 \mathrm{~dB})$ (Table 1). Patients

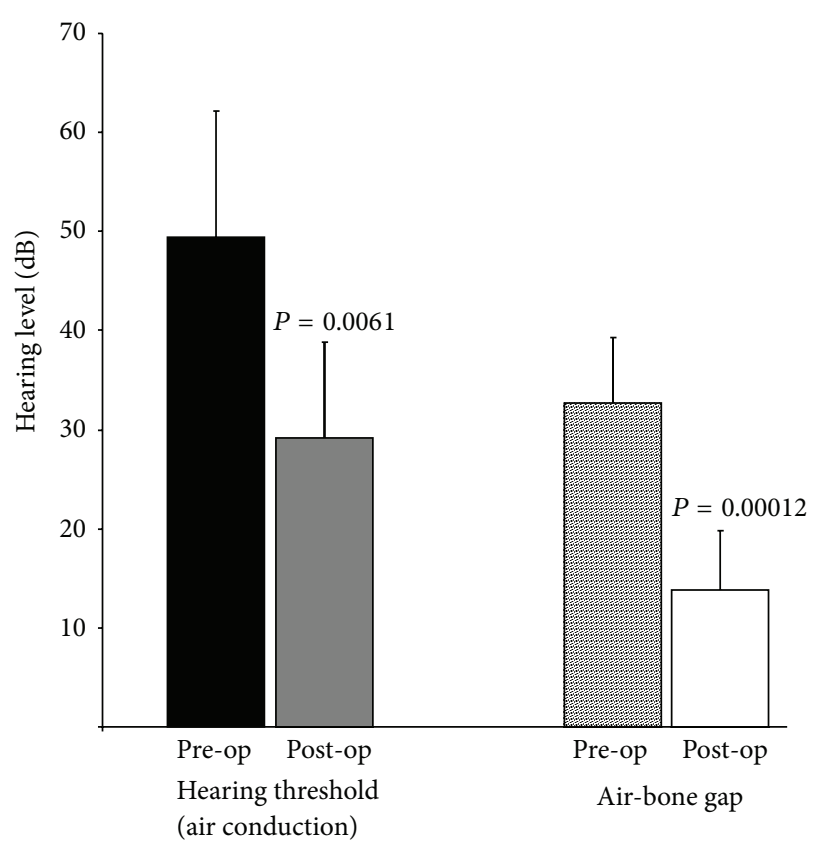

FIGURE 1: Hearing thresholds before and after surgery. Preoperative (pre-op) and postoperative (post-op) hearing thresholds in $\mathrm{db}$ Hearing Level including standard deviation are shown. The first group of two columns (black and grey column, resp.) denotes the hearing threshold on air conduction preoperatively and postoperatively. The second group of two columns denotes the air-bone gap preoperatively and postoperatively (patterned and white column, resp.).

were followed up between 15 and 34 months after surgery, on average $25 \pm 6$ months. Recurrence or prosthesis extrusion was not observed. All patients had a safe dry ear upon clinical examination and reported substantial improvement to their hearing.

Postoperative hearing thresholds (air conduction) in the operated ear had improved to $29.1 \pm 9.7 \mathrm{~dB}(P=0.006)$. The air-bone gap had narrowed to $13.8 \pm 6.0 \mathrm{~dB}$ after surgery (4$24 \mathrm{~dB})(P=0.0001)$. Six patients $(86 \%)$ had a postoperative air-bone gap of less than $20 \mathrm{~dB}$. The air-bone gap closure achieved was on average $18.9 \pm 8.5 \mathrm{~dB}(4-29 \mathrm{~dB}$, Table 1 and 
Figure 1). Representative pre- and postoperative pure tone audiograms are shown in Figure 2.

\section{Discussion}

Middle ear reconstruction following cholesteatoma surgery can be challenging. Auditory ossicles are often eroded, making them insufficient for ossiculoplasty, and they can also harbour remnants of cholesteatoma matrix which can facilitate disease recurrence. Surgical options in these cases include the use of ossicular replacement prostheses or ossicular allografts. Apprehension in using such allografts over a fear of infection transmission has not made them widely known surgical options in recent years and many surgeons have no experience in using them. Tutoplast processed malleus is safe. Since the inception of Tutoplast processed human cadaveric allografts in the 1970s and, there have been no reported cases of graft rejection or disease transmission [2].

Tutoplast processed malleus acts as a collagen matrix for bone regeneration and remodelling. Studies on allograft ossiculoplasty dating back to the 1970s demonstrate that allograft ossicles (notched incus homograft) achieve excellent integration and restoration of hearing [3]. Tutoplast processed bone grafts achieve the highest mesenchymal stem cell adherence in vitro, hence making it an ideal environment for bone regeneration [4]. A study on a postmortem temporal bone confirms minimal resorption of allograft ossicles [5] and longevity of these grafts is excellent, as no osteoclastic bone resorption occurs [6].

Ossicular replacement prostheses are used in middle ear reconstruction with extensively published evidence. A series of 465 cases reported closure of air-bone gap to $\leq 15 \mathrm{~dB}$ in $63 \%$ of cases and to $\leq 20 \mathrm{~dB}$ in $73 \%$ of cases with partial ossicular replacement prostheses (PORP) [7]. A series of 650 cases, also using Plastipore PORP, reported postoperative air-bone gaps of $\leq 20 \mathrm{~dB}$ in $68 \%$, although the average airbone gap was $18 \pm 11 \mathrm{~dB}$ after 12 months [8]. Another group reported postoperative air-bone gap closure $(\leq 20 \mathrm{~dB})$ in tympanoplasty following mastoidectomy for $46 \%$ and $33 \%$ for titanium and hydroxyapatite prostheses, respectively. Average postoperative air-bone gap was $26.5 \mathrm{~dB}$, with $23.8 \mathrm{~dB}$ for titanium group and $29.8 \mathrm{~dB}$ for hydroxyapatite group after 1 year [9]. Closure of the air-bone gap fourteen years following mastoidectomy and tympanoplasty using Plastipore PORP was reported to be $60 \%$ in a group of 5 patients [10].

Tympanoplasty with allogeneic ossicles can restore hearing to levels comparable to autograft, and hearing benefit is often favourable to prostheses. Early reports by Wehrs report a graft take rate between 92 and $96 \%$ and a satisfactory hearing outcome between 77 and 89\% [11]. In a case series on using homologous or autologous incus interposition grafts, there was no significant difference in hearing gain between allografts and autografts. Postoperative air-bone gap was $19 \mathrm{~dB}$, with $66 \%$ of patients achieving an air-bone gap closure of $20 \mathrm{~dB}$ or better after 15 months [12]. Another study on malleus allograft ossiculoplasties reported air-bone gap closure of $\leq 20 \mathrm{~dB}$ in $81 \%$ of cases one year postoperatively, but, in all cases, stapes suprastructure was missing and ossiculoplasty was performed as a secondary procedure, making these outcomes less straightforward to compare [13].

Others report less favourable hearing outcomes compared to autografts or glass ionomer cement. In a study of 293 patients comparing different means of ossicular reconstruction, cholesteatoma removal was the primary cause for surgery in 62 cases (21\%), with a mean postoperative air-bone gap of $15 \pm 8 \mathrm{~dB}$. Allograft ossicles were used in 39 out of 293 cases (13\%), resulting in a postoperative air-bone gap of $13 \pm 9 \mathrm{~dB}$ (mean air-bone gap closure $17 \pm 9 \mathrm{~dB}$ ). There is no distinct group undergoing canal-wall-down mastoidectomy for cholesteatoma using allograft ossicles in this study, which again makes this difficult to compare with other studies [14].

Our postoperative air-bone gap is $13.8 \mathrm{~dB}$. The average closure of the air-bone gap is $18.9 \mathrm{~dB}$, and $86 \%$ of patients had a postoperative air-bone gap of $20 \mathrm{~dB}$ or less. Our outcomes gained from a single-stage procedure exceed the air-bone gap closures reported for PORP in some of the larger studies of tympanoplasty $[7,8]$. They also compare favourably to results achieved in canal-wall-down mastoidectomy $[9,10$, 13]. Moreover, the majority of operations in these studies were performed for chronic suppurative otitis media or were secondary procedures, and canal-wall-down mastoidectomy was either performed as a separate stage or not at all.

In addition to potentially advantageous hearing benefit, allogeneic ossicular grafts integrate into the middle ear and rarely extrude, with historic failure rates between 4 and $8 \%$ [11] and more recent extrusion rates of 0\% [13]. Extrusion rates between $4-5 \%[8,10]$ and $7 \%[7]$ have been reported in studies using prostheses. No extrusion was observed in our series but, due to its low group size, a conclusion on graft extrusion rates is not possible.

\section{Conclusion}

(i) We demonstrate that Tutoplast processed malleus restores hearing in 7 patients undergoing canalwall-down mastoidectomy and tympanoplasty for cholesteatoma.

(ii) We recommend consideration of Tutoplast processed malleus in cases of cholesteatoma where autologous material cannot be used and where a single-step operative procedure to eradicate cholesteatoma with concomitant reconstruction of the middle ear is desired.

(iii) In this small study with a 25-month follow-up, no graft extrusion or other complications were observed, and we are encouraged to offer allograft ossicular reconstruction as an alternative to ossicular prostheses to our patients undergoing mastoid exploration for cholesteatoma who wish to have ossiculoplasty but who have insufficient autologous ossicles.

\section{Conflict of Interests}

The authors declare that there is no conflict of interests regarding the publication of this paper. 

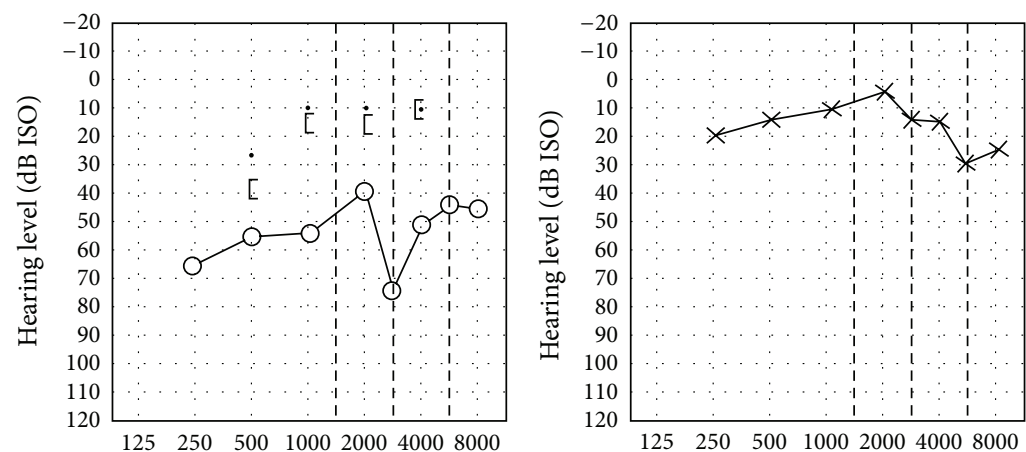

(R) AC masked

(a)
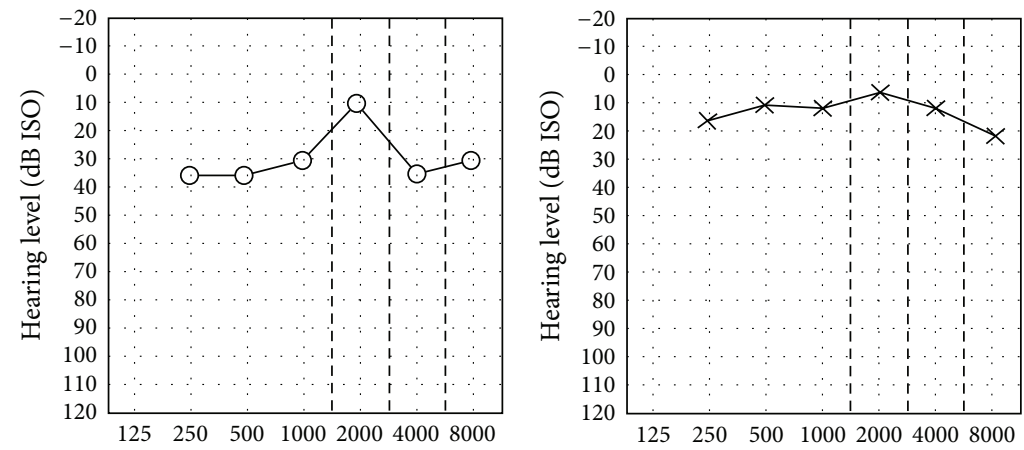

(b)
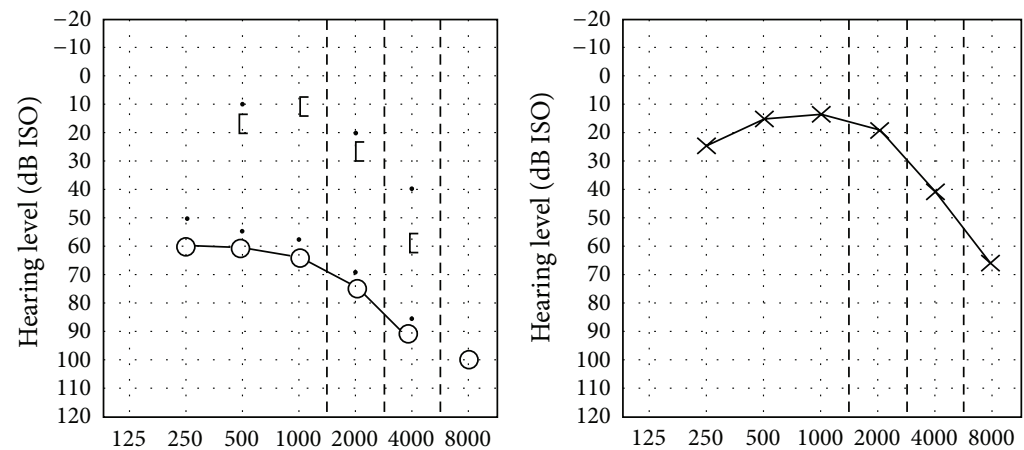

(c)
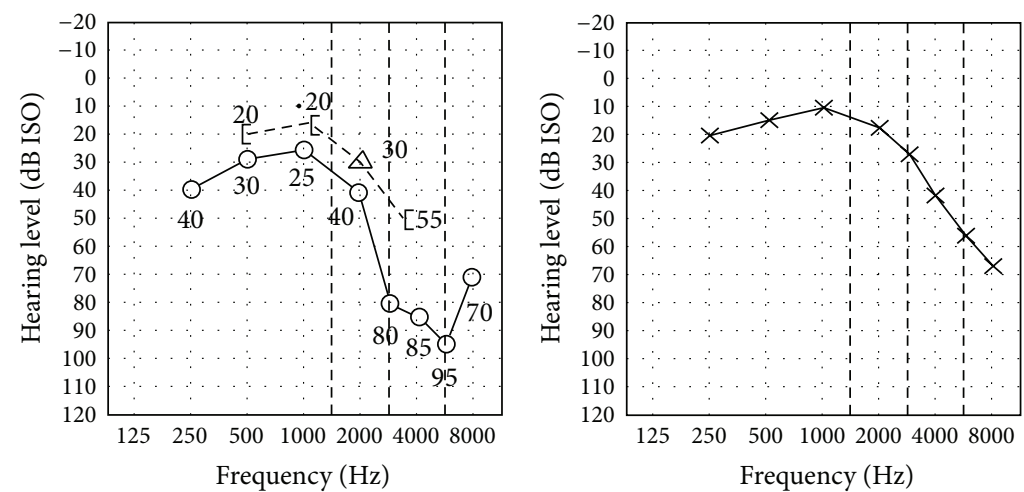

(d)

FIGURE 2: Representative pre- and postoperative original PTA from two patients. Two representative preoperative and postoperative PTA of two patients. Patient 1 (rows (a) and (b)) showed good closure of his operated right ear ABG from $30 \mathrm{~dB}$ to $18 \mathrm{~dB}$ postoperatively. Patient 4 (rows (c) and (d)) showed excellent ABG closure over $29 \mathrm{~dB}$ with a residual ABG of $14 \mathrm{~dB}$ in the operated right ear. 


\section{Acknowledgments}

The authors declare that they have received no funding to support this study. Mr. Wolfgang Issing has received speaker fees from Tutogen Medical GmbH.

\section{References}

[1] C. Schoepf, "Allograft safety: efficacy of the Tutoplast process," Implants-International Magazine of Oral Implantology, vol. 7, no. 1, pp. 10-15, 2006.

[2] Tutogen GmbH, "Der Tutoplast prozess-weltweit einzigartig," http://www.tutogen.de/de/unternehmen/herstellung -tutoplast-prozess.html.

[3] R. E. Wehrs, "Homograft ossicles in tympanoplasty," The Laryngoscope, vol. 92, no. 5, pp. 540-546, 1982.

[4] C. Seebach, J. Schultheiss, K. Wilhelm, J. Frank, and D. Henrich, "Comparison of six bone-graft substitutes regarding to cell seeding efficiency, metabolism and growth behaviour of human mesenchymal stem cells (MSC) in vitro," Injury, vol. 41, no. 7, pp. 731-738, 2010.

[5] V. Goodhill and R. Gussen, "The fate of an ossicular allograft in tympanoplasty," The Laryngoscope, vol. 93, no. 5, pp. 578-582, 1983.

[6] J. Lang, A. G. Kerr, and G. D. Smyth, "Long-term viability of transplanted ossicles," The Journal of Laryngology \& Otology, vol. 100, no. 7, pp. 741-747, 1986.

[7] D. E. Brackmann, J. L. Sheehy, and W. M. Luxford, "TORPs and PORPs in tympanoplasty: a review of 1042 operations," Otolaryngology, vol. 92, no. 1, pp. 32-37, 1984.

[8] J. W. House and K. B. Teufert, "Extrusion rates and hearing results in ossicular reconstruction," Otolaryngology, vol. 125, no. 3, pp. 135-141, 2001.

[9] L. O. Redaelli de Zinis, "Titanium vs hydroxyapatite ossiculoplasty in canal wall down mastoidectomy," Archives of Otolaryngology, vol. 134, no. 12, pp. 1283-1287, 2008.

[10] A. Eleftheriadou, T. Chalastras, S. Georgopoulos et al., "Longterm results of plastipore prostheses in reconstruction of the middle ear ossicular chain," Journal for Oto-Rhino-Laryngology and its Related Specialties, vol. 71, no. 5, pp. 284-288, 2009.

[11] R. E. Wehrs, "Results of homografts in middle ear surgery," The Laryngoscope, vol. 88, no. 5, pp. 808-815, 1978.

[12] R. C. O’Reilly, S. P. Cass, B. E. Hirsch, D. B. Kamerer, R. A. Bernat, and S. P. Poznanovic, "Ossiculoplasty using incus interposition: hearing results and analysis of the middle ear risk index," Otology \& Neurotology, vol. 26, no. 5, pp. 853-858, 2005.

[13] J.-P. Vercruysse, F. E. Offeciers, T. Somers, I. Schatteman, and P. J. Govaerts, "The use of malleus allografts in ossiculoplasty," The Laryngoscope, vol. 112, no. 10, pp. 1782-1784, 2002.

[14] S. A. Felek, H. Celik, A. Islam, A. H. Elhan, M. Demirci, and E. Samim, "Type 2 ossiculoplasty: prognostic determination of hearing results by middle ear risk index," American Journal of Otolaryngology, vol. 31, no. 5, pp. 325-331, 2010. 


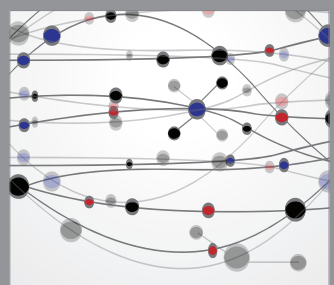

The Scientific World Journal
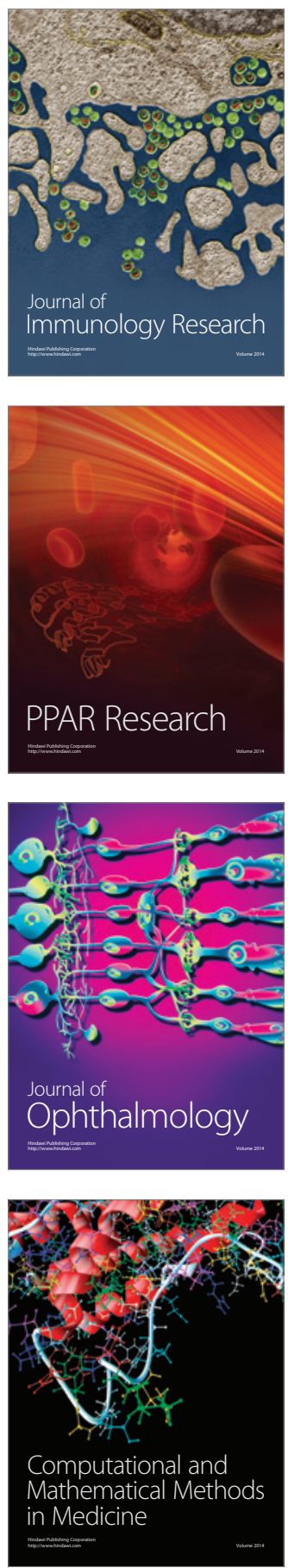

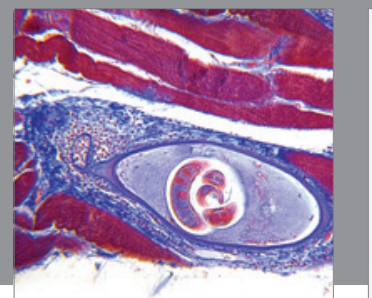

Gastroenterology

Research and Practice
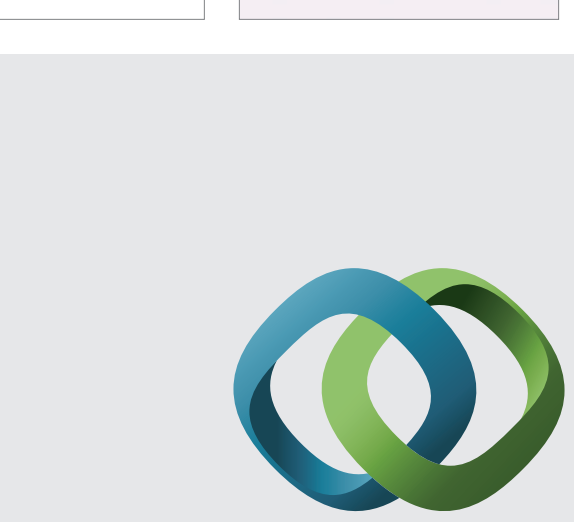

\section{Hindawi}

Submit your manuscripts at

http://www.hindawi.com
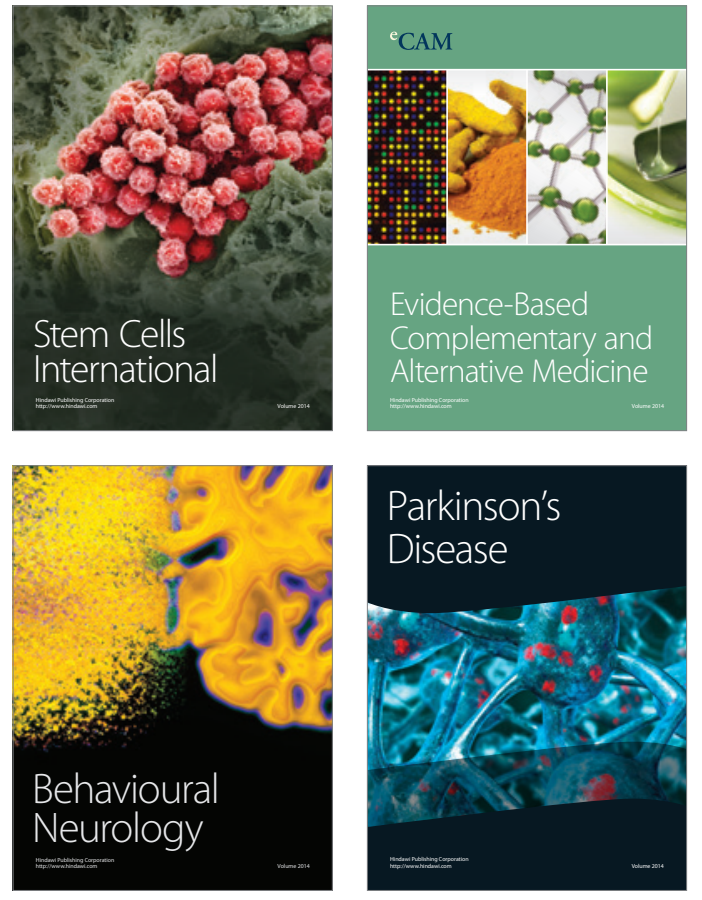
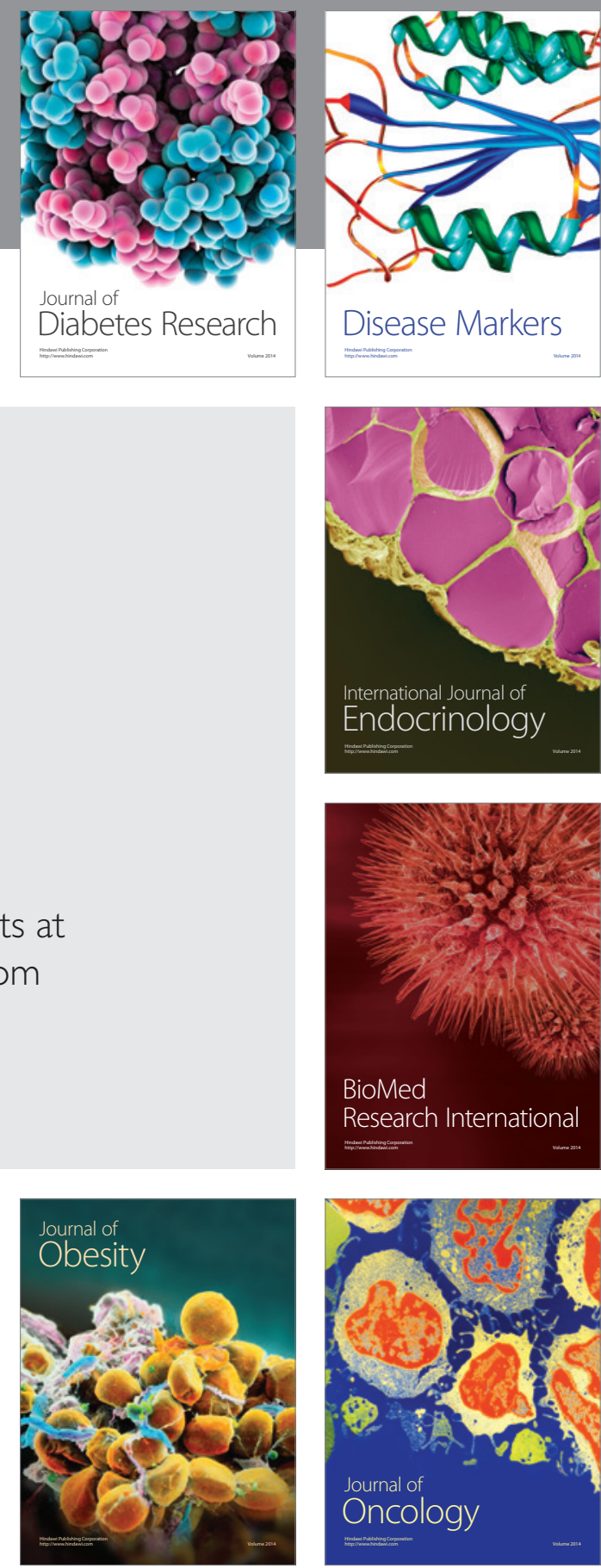

Disease Markers
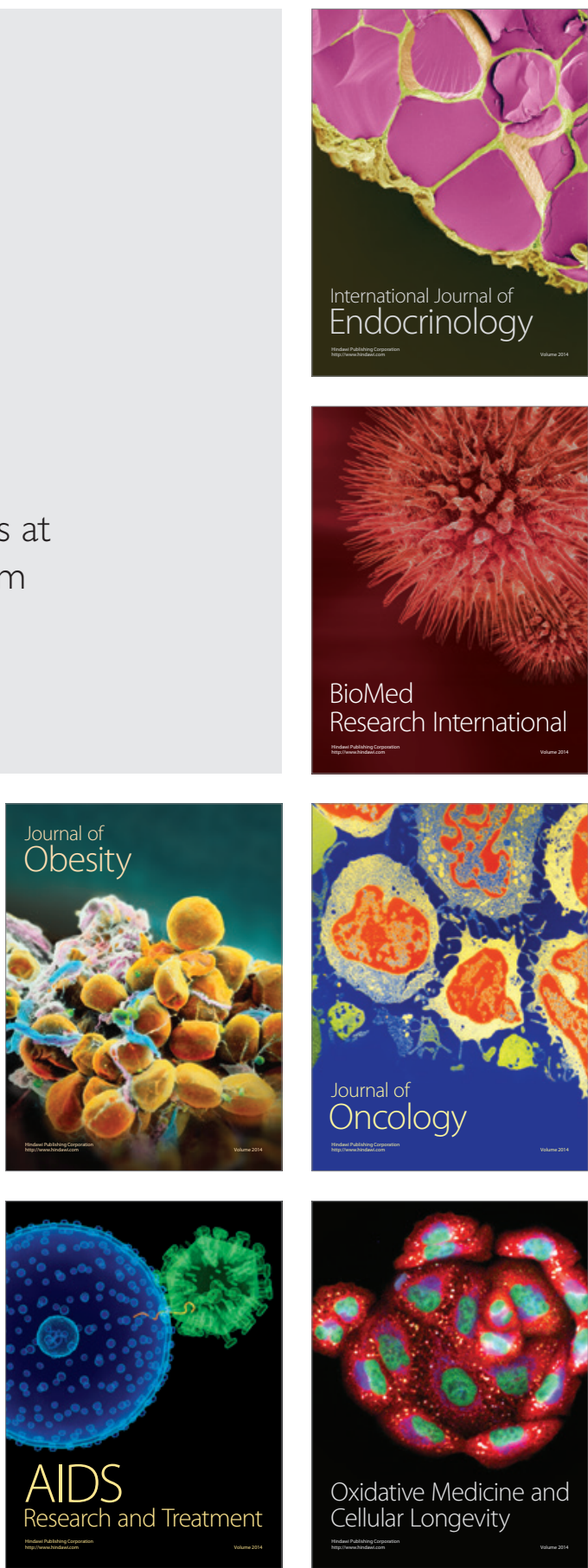